\title{
In-Situ Reduction of Promoted Cobalt Oxide Supported on Alumina by Environmental Transmission Electron Microscopy
}

\author{
Roya Dehghan · Thomas W. Hansen • \\ Jakob B. Wagner • Anders Holmen • \\ Erling Rytter • Øyvind Borg $\cdot$ John C. Walmsley
}

Published online: 2 May 2011

(C) The Author(s) 2011. This article is published with open access at Springerlink.com

\begin{abstract}
Reduction of $12 \mathrm{wt} . \% \mathrm{Co} / 0.5 \mathrm{wt} . \% \mathrm{Re} / \alpha-\mathrm{Al}_{2} \mathrm{O}_{3}$ Fischer-Tropsch catalyst has been studied in-situ in an environmental transmission electron microscope. Reduction of $\mathrm{Co}_{3} \mathrm{O}_{4}$ to metallic cobalt was observed dynamically at $360{ }^{\circ} \mathrm{C}$ under $3.4 \mathrm{mbar}_{2}$. Structural and morphological changes were observed by high resolution transmission electron microscopy and scanning transmission electron microscopy imaging. The cobalt particles were mainly face centred cubic while some hexagonal close packed particles were also found. Reoxidation of the sample upon cooling to room temperature, still under flowing $\mathrm{H}_{2}$, underlines the reactivity of the nanoparticles and the importance of controlling the gas composition and specimen temperature during this type of experiment. Similar behaviour was observed for a non-promoted catalyst. Imaging and analysis of the promoted sample before and after reduction indicated a uniform distribution of the promoter.
\end{abstract}

\author{
R. Dehghan $(\bowtie)$. J. C. Walmsley \\ Department of Physics, Norwegian University of Science \\ and Technology (NTNU), 7491 Trondheim, Norway \\ e-mail: roya.dehghan@ntnu.no \\ T. W. Hansen · J. B. Wagner \\ Center for Electron Nanoscopy, Technical University of \\ Denmark (DTU), 2800 Lyngby, Denmark \\ A. Holmen · E. Rytter \\ Department of Chemical engineering, (NTNU), 7491 \\ Trondheim, Norway \\ E. Rytter $\cdot \varnothing$. Borg \\ Statoil R\&D, Research Centre, Postuttak, 7005 Trondheim, \\ Norway \\ J. C. Walmsley \\ SINTEF Materials and Chemistry, 7465 Trondheim, Norway
}

Keywords Environmental transmission electron microscopy $\cdot$ Fischer-Tropsch $\cdot$ In-situ $\cdot$ Reduction $\cdot$ Cobalt

\section{Introduction}

Cobalt nanoparticles on a porous support, typically alumina, are widely used in Fischer-Tropsch (FT) processes to convert natural gas into synthetic fuel. To optimize the efficiency of these catalysts and the FT process, a fundamental understanding of the catalyst structure and behaviour must be obtained on the nanometre scale [1]. Dispersion, morphology and distribution of the particles are important in understanding the selectivity and activity of the catalyst. Among available techniques, Transmission Electron Microscopy (TEM) is a powerful tool for the direct study of catalyst systems. One challenge is to study the catalyst as close as possible to the condition in which it functions. While the industrial conditions at which FT synthesis takes place, $20-30$ bar at $220-240{ }^{\circ} \mathrm{C}$ [2], are not accessible in the TEM, in-situ experiments can be conducted in Environmental TEM (ETEM) instruments [3-5]. Instruments with differentially pumped columns can provide operating pressures in the range up to 20 mbar [6]. Closed reaction cells with electron transparent windows have demonstrated pressures up to 1 bar [7].

Cobalt needs to be in the metallic state in order to be active in the FT process. The reduction sequence is from $\mathrm{Co}_{3} \mathrm{O}_{4}$ to $\mathrm{CoO}$ and to catalytically active metallic cobalt. The cobalt metal nanoparticles oxidize rapidly when exposed to the ambient atmosphere. The structures of $\mathrm{Co}_{3} \mathrm{O}_{4}, \mathrm{CoO}$ and cobalt are spinel, rock salt and hexagonal close packed (hcp) or face centred cubic (fcc), respectively $[8,9]$. The corresponding volume decrease on going from $\mathrm{Co}_{3} \mathrm{O}_{4}$ to $\mathrm{CoO}$ is $12 \%$ and from $\mathrm{Co}_{3} \mathrm{O}_{4}$ to hexagonal or 
Table 1

\begin{tabular}{|c|c|c|c|c|c|c|}
\hline $\begin{array}{l}\text { Co } \\
\text { Hexagonal } \\
\left(\mathrm{a}_{0}=2.507,\right. \\
\left.\mathrm{c}_{0}=4.070\right)\end{array}$ & $\begin{array}{l}\text { Co } \\
\text { Cubic } \\
(\text { Fm3m, } \\
\left.\mathrm{a}_{0}=3.5447\right)\end{array}$ & $\begin{array}{l}\mathrm{CoO} \\
\mathrm{Cubic} \\
(\mathrm{Fm} 3 \mathrm{~m}, \\
\left.\mathrm{a}_{0}=4.260\right)\end{array}$ & $\begin{array}{l}\mathrm{Co}_{3} \mathrm{O}_{4} \\
\text { Cubic } \\
(\mathrm{Fd} 3 \mathrm{~m} \\
\left.\mathrm{a}_{0}=8.084\right)\end{array}$ & $\begin{array}{l}\alpha-\mathrm{Al}_{2} \mathrm{O}_{3} \\
\text { Trigonal }(\mathrm{P} 63 / \mathrm{mmc} \\
\mathrm{a}_{0}=4.758 \\
\left.\mathrm{c}_{0}=12.991\right)\end{array}$ & $\begin{array}{l}\mathrm{Re} \\
\text { Hexagonal } \\
\left(\mathrm{a}_{0}=2.760,\right. \\
\left.\mathrm{c}_{0}=4.458\right)\end{array}$ & $\begin{array}{l}\mathrm{CoAl}_{2} \mathrm{O}_{4} \\
\text { Cubic } \\
(\mathrm{Fd} 3 \mathrm{~m}, \\
\left.\mathrm{a}_{0}=8.103\right)\end{array}$ \\
\hline $2.16(100)$ & 2.05 & $2.46(111)$ & 4.67 (111) & 3.47 (012) & $2.38(100)$ & 4.68 (111) \\
\hline $2.02(002)$ & $1.77(200)$ & $2.13(200)$ & $2.86(220)$ & 2.55 (104) & $2.23(002)$ & $2.86(220)$ \\
\hline $1.91(101)$ & $1.25(220)$ & $1.51(220)$ & $2.43(311)$ & 2.08 (113) & 2.10 & $2.44(311)$ \\
\hline $1.49(102)^{\mathrm{a}}$ & $1.06(311)$ & $1.28(311)$ & $2.02(400)$ & $1.96(202)$ & $1.38(110)$ & $2.03(400)$ \\
\hline 1.25 (110) & $1.02(222)$ & $1.23(222)$ & $1.43(440)$ & $1.40(124)$ & 1.17 (112) & $1.43(440)$ \\
\hline
\end{tabular}

a This reflection is forbidden for metallic cobalt

cubic cobalt is $49 \%$. At temperatures above $450{ }^{\circ} \mathrm{C}$, bulk metallic cobalt has the fcc structure, while at lower temperatures the hcp cobalt structure is stable $[10,11]$. Supported cobalt nanoparticles tend to form with both fcc and hcp cobalt structures at low temperatures, even below the bulk transition temperature [11, 12]. Lattice structures and major lattice spacings for the known cobalt phases and the alumina support are given in Table 1. Spacings for $\mathrm{CoAl}_{2} \mathrm{O}_{4}$ and metallic rhenium are also included. The formation of $\mathrm{CoAl}_{2} \mathrm{O}_{4}$ during reduction has been discussed by Jongsomjitt et al. [13].

Two TEM studies of in-situ and ex-situ reduction of $\mathrm{Co}_{3} \mathrm{O}_{4}$ supported on $\gamma-\mathrm{Al}_{2} \mathrm{O}_{3}$ have been reported. $\mathrm{Li}$ et al. [4] conducted experiments on $20 \mathrm{wt} . \% \mathrm{Co} / \gamma-\mathrm{Al}_{2} \mathrm{O}_{3}$ and $20 \mathrm{wt} . \% \mathrm{Co} / 2 \mathrm{wt} . \% \mathrm{Ru} / \gamma-\mathrm{Al}_{2} \mathrm{O}_{3}$ in an in-situ TEM at $400{ }^{\circ} \mathrm{C}$ in 1.3 mbar of $10 \% \mathrm{H}_{2} / 90 \% \mathrm{~N}_{2}$. Larger cobalt particles were reduced to $\mathrm{CoO}$, while in the promoted sample small particles of metallic $\mathrm{CoRu}$ or pure $\mathrm{Ru}$ were also formed. Ozkaya et al. [14] used an $e x$-situ holder, in which a sample with $20 \%$ wt.Co $/ \gamma-\mathrm{Al}_{2} \mathrm{O}_{3}$ was exposed to gas at elevated temperature in an integrated reaction cell so that the sample was not exposed to ambient atmosphere between reaction and observation. Reduction was conducted at $400{ }^{\circ} \mathrm{C}$ and 4 mbar of $10 \% \mathrm{H}_{2} / 90 \% \mathrm{~N}_{2}$. The $\mathrm{Co}_{3} \mathrm{O}_{4}$ precursor was reduced to $\mathrm{CoO}$ but not metallic cobalt.

Here we report on the reduction of $\mathrm{Co}_{3} \mathrm{O}_{4}$ nanoparticles, observing changes in crystallography and morphology. We demonstrate in-situ TEM observations of the reduction of $\mathrm{Co}_{3} \mathrm{O}_{4}$ particles supported on $\alpha-\mathrm{Al}_{2} \mathrm{O}_{3}$ to metallic cobalt.

\section{Experimental}

\subsection{Sample preparation}

The FT catalyst was synthesized through one-step incipient wetness impregnation of alumina support with an aqueous solution of cobalt nitrate hexahydrate, $\mathrm{Co}\left(\mathrm{NO}_{3}\right)_{2} \cdot 6 \mathrm{H}_{2} \mathrm{O}$, and perrhenic acid, $\mathrm{HReO}_{4}$, to provide a rhenium promoter.
The cobalt and rhenium loadings on the $\alpha-\mathrm{Al}_{2} \mathrm{O}_{3}$ support were 12 and $0.5 \mathrm{wt} \%$, respectively. The catalyst was dried at $110{ }^{\circ} \mathrm{C}$ for $3 \mathrm{~h}$ after impregnation. The dried sample was calcined in air at $300{ }^{\circ} \mathrm{C}$ for $16 \mathrm{~h}$ to form cobalt oxide particles with a composition $12 \mathrm{wt} . \% \mathrm{Co} / 0.5 \mathrm{wt} . \% \mathrm{Re} /$ $\alpha-\mathrm{Al}_{2} \mathrm{O}_{3}$. A ramping rate of $2{ }^{\circ} \mathrm{C} / \mathrm{min}$ was used to heat the samples from ambient temperature to the final calcination temperature. XRD analysis of the sample gives an average crystallite size of $21 \mathrm{~nm}$ for the $\mathrm{Co}_{3} \mathrm{O}_{4}$ phase and $94 \mathrm{~nm}$ for the $\alpha-\mathrm{Al}_{2} \mathrm{O}_{3}$. For comparison, some results from non-promoted catalyst are also presented. This was produced by the same route except that $\mathrm{HReO}_{4}$ was not added to the precursor and the final composition was $12 \mathrm{wt} . \% \mathrm{Co} /$ $\alpha-\mathrm{Al}_{2} \mathrm{O}_{3}$.

\subsection{TEM analysis}

TEM samples for in-situ experiments were prepared by dispersion of crushed powder directly onto stainless steel grids. This provides good thermal contact between grid and catalyst. TEM analysis was performed with an FEI TITAN ETEM operating at $300 \mathrm{kV}$. This microscope is equipped with a differential pumping system, making it possible to study materials under controlled gas flows and at elevated temperatures. The sample region is differentially pumped and the gas supply circuit is independent of the main vacuum system. Heating is by a thermal resistance heater in the sample holder and the temperature is measured by a thermocouple. The instrument has a $\mathrm{C}_{\mathrm{S}}$ image corrector which increases the resolution of the instrument well into the sub-Angstrom regime [6]. The ETEM is equipped with a residual gas analyser (RGA) that allows the composition of the environment in the sample region to be monitored.

For each experiment, the sample was studied before introduction of $\mathrm{H}_{2}$ and heating. Several positions were examined by High Resolution TEM (HRTEM), High Angle Annular Dark Field (HAADF) Scanning TEM (STEM) imaging and Electron Energy-Loss Spectroscopy (EELS). After initial observation, $\mathrm{H}_{2}$ was introduced into 
the region of the sample, to a stable pressure of $3.4 \mathrm{mbar}$ and the temperature was gradually increased to $360{ }^{\circ} \mathrm{C}$. The reduction reaction was monitored by recording TEM images of one of the selected regions of the sample at intervals of $0.8 \mathrm{~s}$. These images were subsequently combined into movies showing the reduction process. After reduction the sample was analysed again by HRTEM, STEM and EELS. After analysis, the temperature was decreased to room temperature under continuous $\mathrm{H}_{2}$ flow.

It is important to consider the possible influence of the electron beam on ETEM experiments. Beside ionisation and knock-on damage of the sample, the beam interaction with the gas consists of both incident high energy electrons and low energy secondary electrons which are emitted from the specimen and cause ionisation of the gas molecules [6]. To verify the influence of beam on the reduction experiment, blank reduction (with the absence of electron beam) was carried out and reduction was confirmed by EELS analysis.

Electron dose for acquisition at low magnification was about $10^{2} \mathrm{e} / \mathrm{nm}^{2} \mathrm{~s}$ and for acquisitions at high magnification was about $2 \times 10^{5} \mathrm{e} / \mathrm{nm}^{2}$ s. Reduction was generally followed at low magnification, with the electron beam spread over a large area around one sample grid bar. Detailed examination of individual catalyst particles was then conducted after no further changes to the sample were observed. The reduction behaviour of catalyst particles which had not been exposed to the electron beam was confirmed by observing positions that had not been exposed to the electron beam during the initial reduction.

Energy Dispersive X-ray Spectroscopy (EDS) analysis was performed in a JEOL 2010F which is a Field Emission Gun (FEG) TEM and operates at $200 \mathrm{kV}$ accelerating voltage. EDS was performed on both reduced and nonreduced promoted samples. Reduced material was transferred from glove box to the TEM by using glove bag. TEM samples for these experiments were prepared by dispersion of crushed powder on carbon film supported with copper mesh grid.

\section{Results}

The microstructure of the promoted sample before reduction is shown in Fig. 1. Figure 1a is a low magnification overview of the microstructure, showing the darker $\mathrm{Co}_{3} \mathrm{O}_{4}$ phase dispersed on the much coarser alumina grains. Some of the $\mathrm{Co}_{3} \mathrm{O}_{4}$ crystallites are grouped into aggregates, which are considerably larger than the $21 \mathrm{~nm}$ particle size measured by XRD. Examples of these are indicated by arrows. Figure $1 \mathrm{~b}$ shows lattice resolution images of an enlarged area of Fig. 1a. Lattice spacings were measured directly from the image. In Fig. $1 \mathrm{~b}$ the measured lattice spacings of $4.66 \AA$ corresponds to the (111) planes of $\mathrm{Co}_{3} \mathrm{O}_{4}$, Table 1 .

\subsection{Movie of reduction}

Figure 2a and $\mathrm{b}$ show the same area as Fig. 1a and $\mathrm{b}$ after reduction, respectively. Figure $2 c$ shows a HRTEM image of a different cobalt particle after reduction. HRTEM images confirm that the reduction of $\mathrm{Co}_{3} \mathrm{O}_{4}$ to cobalt has been achieved successfully. Where overlap exists in spacings between cobalt metal and substrate, it is possible to distinguish the two phases on the basis of morphology and spatial distribution. According to Table 1, the features with lattice spacings of 1.91 and $2.16 \AA$ are identified as hcp metallic cobalt and the features with lattice spacings of $2.05 \AA$ (Fig. 2c) as fcc metallic cobalt. Lattice spacings of $2.02 \AA$ could also be $\mathrm{Co}_{3} \mathrm{O}_{4}$. However, before reduction, the main lattice spacing representative of $\mathrm{Co}_{3} \mathrm{O}_{4}$ was $4.66 \AA$ and in HRTEM images after reduction there is no evidence of that spacing in the images recorded. This strongly suggests that all the $\mathrm{Co}_{3} \mathrm{O}_{4}$ has been reduced to metallic cobalt.

Further confirmation of complete reduction of $\mathrm{Co}_{3} \mathrm{O}_{4}$ was provided by EELS. Figure 3 shows EELS spectra acquired from Co-phases before and after reduction. In spectrum 1, which was acquired from a $\mathrm{Co}_{3} \mathrm{O}_{4}$ particle before reduction, the $\mathrm{O}-\mathrm{K}$ edges (at $532 \mathrm{eV}$ ) and $\mathrm{Co}-\mathrm{L}_{2,3}$ edges (at $779 \mathrm{eV}$ ) are present. Spectrum 2, acquired from a cobalt particle after reduction, shows only a Co- $\mathrm{L}_{2,3}$ edge and no measurable signal from oxygen. Figure 4 compares the EELS Spectra obtained from alumina and $\mathrm{Co}_{3} \mathrm{O}_{4}$ in the same energy range. Spectrum 1 shows the $\mathrm{O}-\mathrm{K}$ edge in alumina and spectrum 2 shows $\mathrm{O}-\mathrm{K}$ and $\mathrm{Co}-\mathrm{L}_{2,3}$ edges in $\mathrm{Co}_{3} \mathrm{O}_{4}$. Comparison shows that the oxygen near edge fine structure obtained from $\mathrm{Co}_{3} \mathrm{O}_{4}$ and alumina is different. The first near-edge peak (indicated in the spectrum) from $\mathrm{Co}_{3} \mathrm{O}_{4}$ is not present in the alumina spectrum. Similar EELS spectra for $\mathrm{Co}_{3} \mathrm{O}_{4}$ and $\mathrm{CoO}$ were presented and discussed by Li et al. [4].

Figure 5 shows STEM images of the sample. Cobalt aggregates on the larger support grains show bright contrast relative to the substrate. STEM images are sensitive to atomic number and density and show the changes in morphology after reduction clearly. Figure $5 \mathrm{a}$ and $\mathrm{b}$ are images before reduction and Fig. $5 \mathrm{c}$ and $\mathrm{d}$ are images of the same area after reduction. Figure $5 \mathrm{c}$ and $\mathrm{d}$ show that the cobalt containing phase has become dense. Furthermore, the original $\mathrm{Co}_{3} \mathrm{O}_{4}$ aggregates show evidence of having separated into more distinct, individual, particles. This shrinking behaviour is consistent with the reduction in volume associated with the reduction process described in the introduction. This is also important from the catalytic 


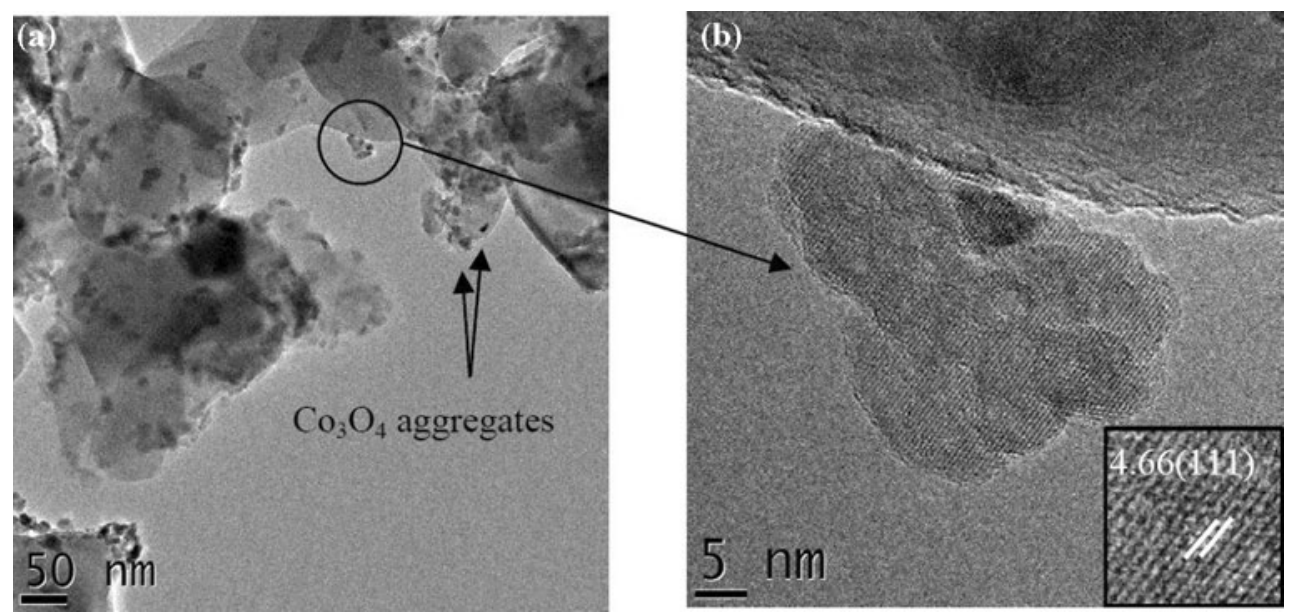

Fig. 1 Images of catalyst before reduction. a Low magnification image of $\mathrm{Co}_{3} \mathrm{O}_{4}$ on alumina support, arrows indicate $\mathrm{Co}_{3} \mathrm{O}_{4}$ aggregates. b HRTEM detail of a single $\mathrm{Co}_{3} \mathrm{O}_{4}$ aggregate
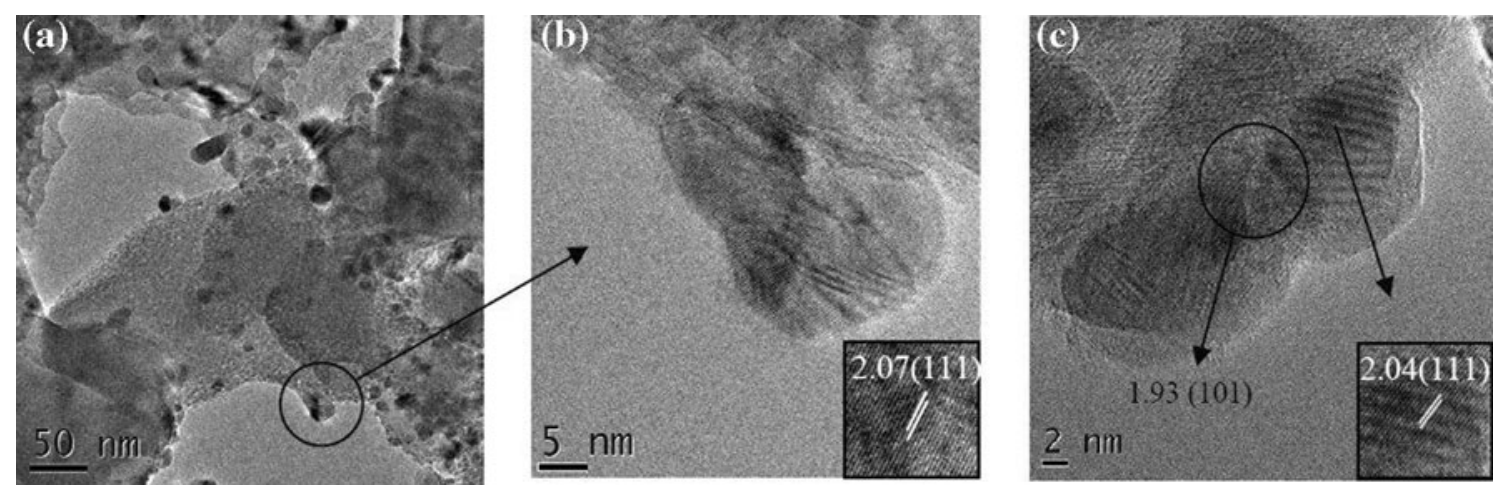

Fig. 2 Images of the catalyst after reduction. a Low magnification TEM image of catalyst, $\mathbf{b}$ HRTEM image of cobalt aggregate at $\mathrm{T}=360{ }^{\circ} \mathrm{C}$ and in $3.4 \mathrm{mbar}_{2}$ gas, which shows a lattice spacings for fcc cobalt $\mathbf{c}$ HRTEM image showing lattice spacing for both fcc and hcp cobalt

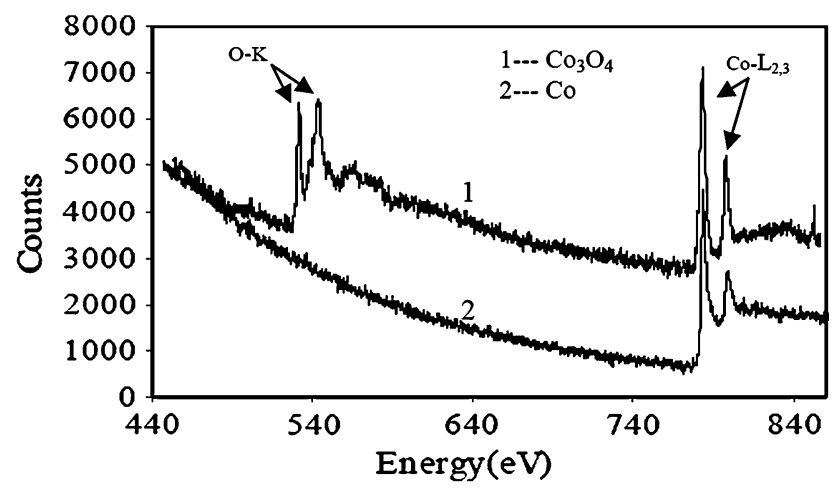

Fig. 3 EELS spectra recorded before and after reduction

point of view as it provides a larger surface area of metal than if the particles were to coalesce.

After reduction the sample was allowed to cool down to room temperature in $\mathrm{H}_{2}$. It was found that the cobalt nanoparticles had partially re-oxidized. Figure 6a shows a cobalt aggregate after reduction, some minutes after cooling to room temperature and still under $\mathrm{H}_{2}$ flow. In this

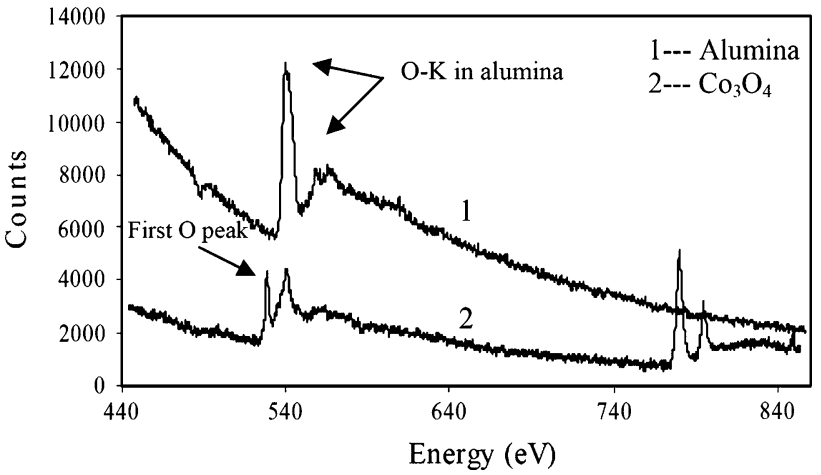

Fig. 4 EELS spectra of alumina and $\mathrm{Co}_{3} \mathrm{O}_{4}$

image some areas show lattice spacings of $2.86 \AA$, which corresponds with (220) planes of $\mathrm{Co}_{3} \mathrm{O}_{4}$, and some parts show lattice spacings of $2.13 \AA$ which corresponds with (200) planes of CoO.

After analysis, the sample was kept inside the microscope overnight, without $\mathrm{H}_{2}$ flow and the result was further 
Fig. 5 STEM images before reduction. b Magnified area of a. c The same area as a after reduction. e Magnified area of $\mathbf{d}$ and after reduction. a Before
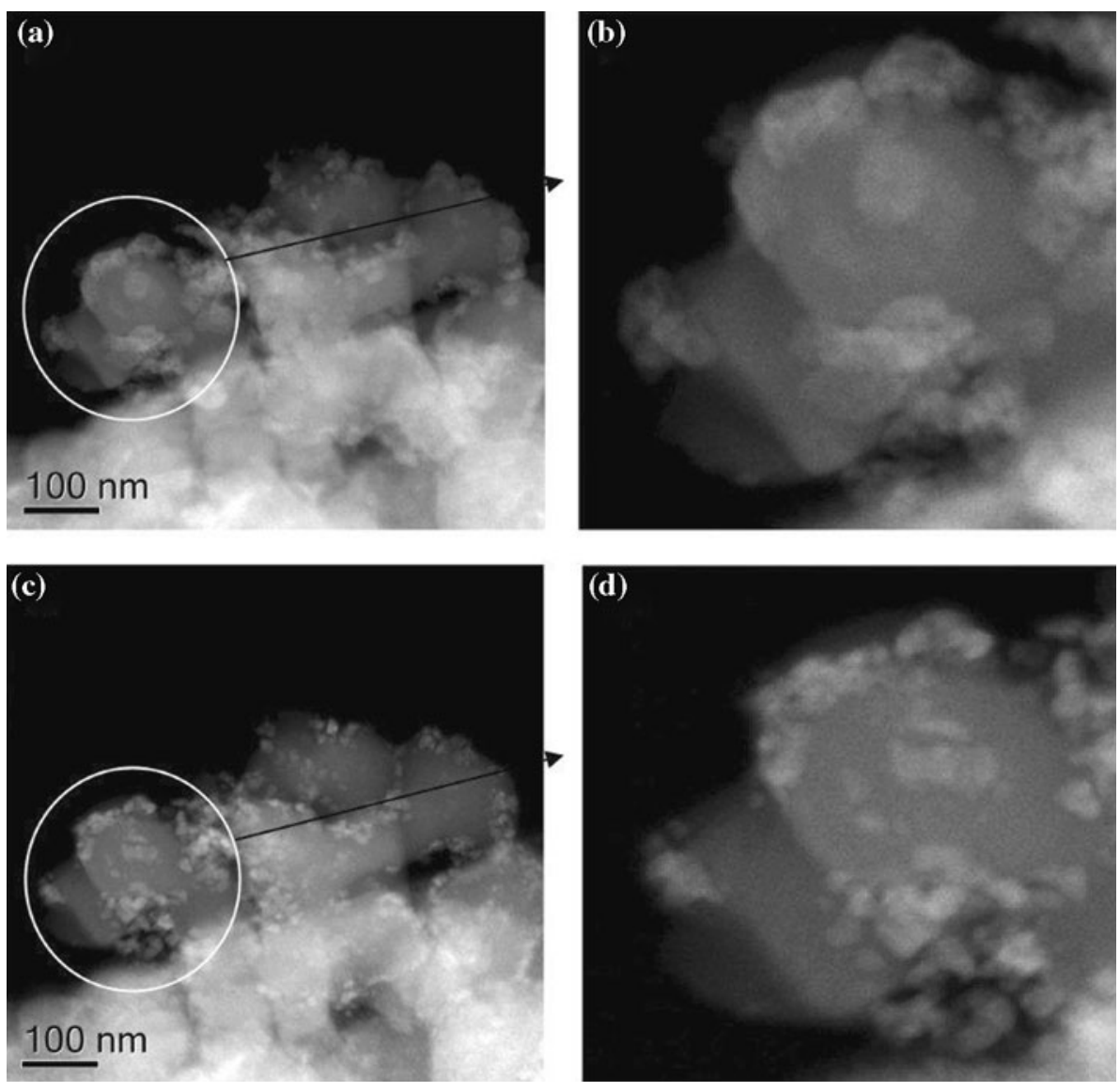

Fig. 6 a HRTEM image showing reoxidation. a Image of cobalt aggregate at room temperature and under $\mathrm{H}_{2}$ flow. b HRTEM image of particle shown in Figs. $1 \mathbf{b}$ and $2 \mathbf{b}$ after being left overnight in the TEM vacuum
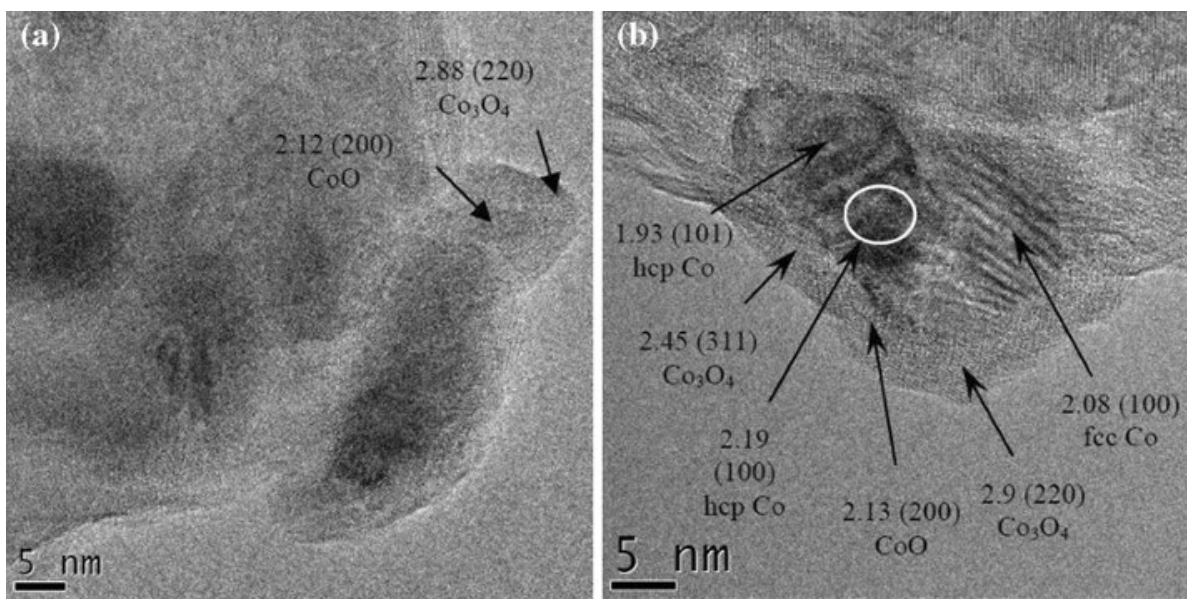

partial oxidation of cobalt. Figure $6 \mathrm{~b}$ shows a layer with approximately $3 \mathrm{~nm}$ thickness of oxide around a cobalt particle. Lattice fringes confirm that the outer layer of oxide contains the characteristic $d$ values of $2.86 \AA$, $2.46 \AA$ for $\mathrm{Co}_{3} \mathrm{O}_{4}$ and $2.13 \AA$ for $\mathrm{CoO}$, respectively. The fringes in the inner layer show the $d$ value of $1.91 \AA, 2.16 \AA$, which correspond with (100) and (101) planes of hexagonal cobalt and $2.05 \AA$ which corresponds with (111) planes of fcc cobalt. Generally, a structure with the most oxygen-rich oxide on the outside and the metal in the centre is seen.
This is consistent with slow oxidation of the particles, which requires transport of oxygen through the stable outer layer of $\mathrm{Co}_{3} \mathrm{O}_{4}$.

As described above, areas in the sample that had not been previously exposed to the electron beam were examined after reduction. Figure 7 shows analysis from such an area. Figure 7a shows STEM image and Fig. 7b shows an EELS spectrum from that area in which the oxygen signal is absent. After reduction the structure of these cobalt nanoparticles was similar to that observed in 
the areas observed at low magnification under the electron beam during reduction, confirming that electron beam irradiation did not have a significant influence on the reduction process. However, in the areas of the specimen which were under the beam for repeated heating and cooling and where single particles were examined at higher magnification, and correspondingly higher beam current density, some beam damage of the sample was observed.

No distinct rhenium particles were observed during examination of the promoted sample, either from measurements of characteristic lattice parameters from Table 1 or from strong contrast in HAADF images that would be expected from the large difference in atomic number with cobalt. It is not possible to perform EDS in the sample heating holder that was used for the reduction experiments, due to the furnace of the heating element. In addition, rhenium is not easily studied by EELS as the major edge, $\mathrm{O}_{2,3}$ at $35 \mathrm{eV}$, overlaps with peaks from other elements and the $\mathrm{M}_{4,5}$ at $\sim 1900 \mathrm{eV}$ with a delayed maximum, is at too high an energy for efficient analysis. Li et al. [4] were able to use EELS to study the distribution of $\mathrm{Ru}$ catalyst in a promoted $\mathrm{Co} / \gamma-\mathrm{Al}_{2} \mathrm{O}_{3}$ catalyst and found that the promoter was concentrated in small $\mathrm{Ru}$ or bimetallic RuCo particles alongside larger $\mathrm{CoO}$ particles after in-situ reduction of the catalyst.

EDS analysis was performed on the reduced promoted sample, $12 \mathrm{wt} . \% \mathrm{Co} / 0.5 \mathrm{wt} . \% \mathrm{Re} / \alpha-\mathrm{Al}_{2} \mathrm{O}_{3}$, and same analysis was performed on the same sample before reduction. The results were not reproduced here. However, in both cases analysis showed the presence of a weak Re signal, consistent with the overall stoichiometry of the sample. No local concentration of Re was observed, either with cobalt or as separate particles.

Figure 8 shows analysis of cobalt particles in the nonpromoted sample after reduction. Figure 8a shows fcc metallic lattice fringes with spacing of $2.05 \AA$ in the particles, corresponding to fcc metallic cobalt. Figure $8 b$ shows the EELS spectrum from a reduced particle. The very weak oxygen edge can be attributed to a small contribution from the alumina substrate and in spectra where the oxygen peak was stronger the pre-edge structure associated with Co-oxide was absent.

\section{Discussion}

ETEM experiments allow in-situ study of the morphology of catalysts cobalt nanoparticles during exposure to a reducing gas. This can have an important role in understanding the reduction mechanisms, interface interaction and regeneration of supported metal catalysts [15].

The results show that it is possible to reduce the cobalt oxide particles at $360{ }^{\circ} \mathrm{C}$ with $\mathrm{H}_{2}$ gas in-situ in the ETEM and to follow the particles during reduction. The availability of spherical aberration correction on the objective lens system gives a significant improvement in the level of information that can be obtained from samples. For example, minimising image delocalisation, especially near the edges of the particles makes it easier to interpret the surfaces and facets structures and reduces the electron dose to the sample for the same amount of information $[6,16]$.

It is of interest to know the crystal structure of the metallic cobalt particles and to know the distribution of fcc and hcp cobalt between them. The main lattice spacing which confirms the presence of fcc cobalt is $2.05 \AA$, which is close to the lattice of $2.02 \AA$ spacing for hexagonal cobalt. In order to determine the accuracy of the measurements, measurements were made on about 20 recognizable spacings on the HRTEM images of the $\alpha-\mathrm{Al}_{2} \mathrm{O}_{3}$ and cobalt oxide phases on the images from the same session or similar sessions. The results give an average of $\approx 1 \%$ error on the fringe measurements. With this accuracy it is challenging to distinguish between similar spacings in fcc and hcp cobalt but it is possible. The results indicate that small aggregates $(7-20 \mathrm{~nm})$ have only fcc structure after reduction, while the aggregates with the size between 20 and $30 \mathrm{~nm}$ have a mixture of hcp and fcc structure. One large particle, with a size of $30 \mathrm{~nm}$, gave spacings consistent with being hcp. The in-situ TEM analyses were done at $360{ }^{\circ} \mathrm{C}$, which is lower than the limit for the
Fig. 7 Analysis of a particle that was not exposed to the electron beam during reduction. a STEM image. b EELS spectrum
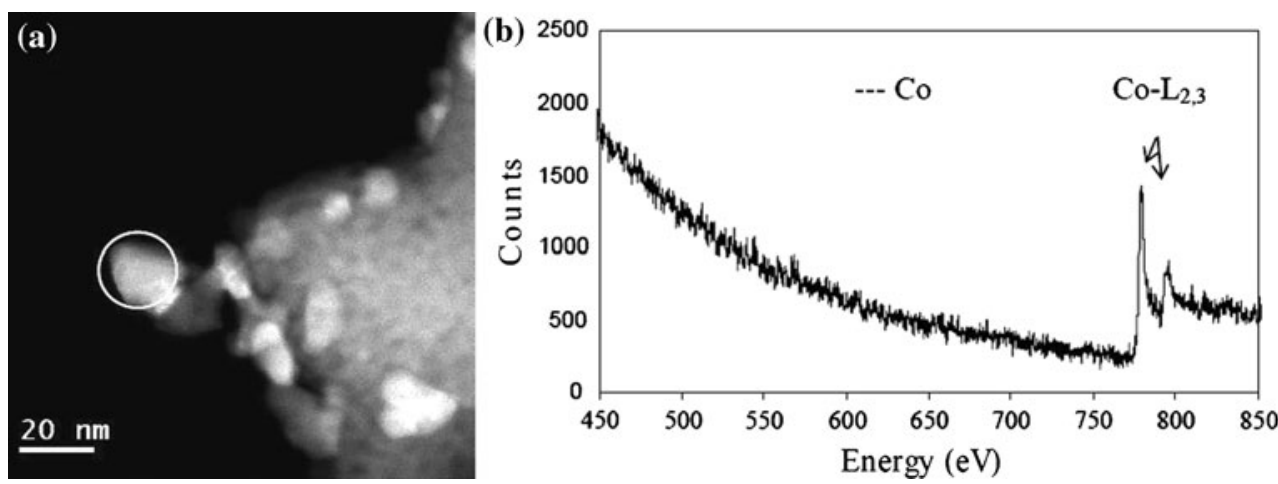
Fig. 8 Reduced Co particle in non-promoted material. a HRTEM image. b EELS spectrum
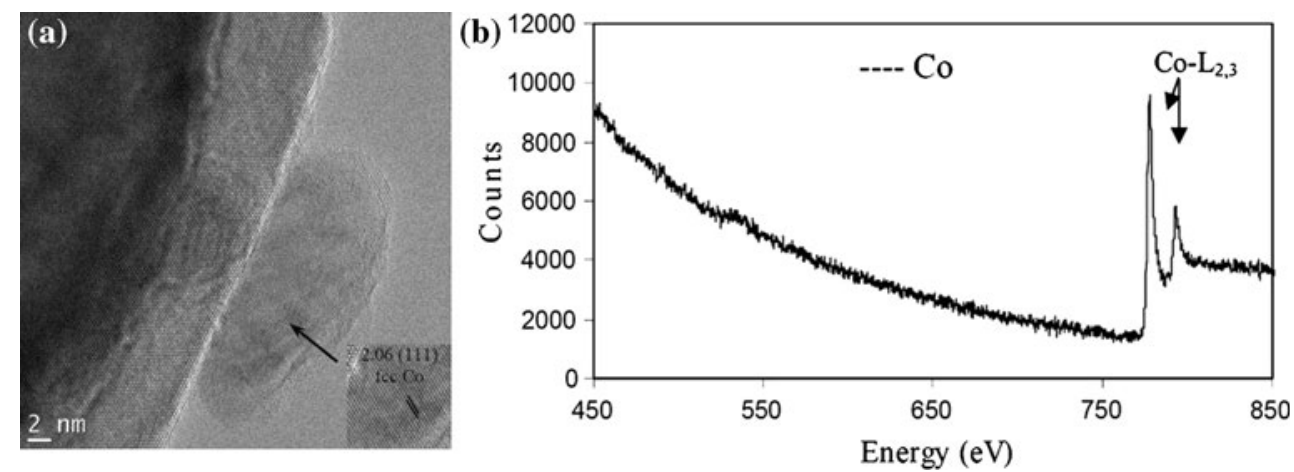

transition between fcc and hcp in the bulk. The literature clearly shows a size effect for cobalt nanoparticles. The in-situ XRD reduction of Co-oxide supported on $\gamma-\mathrm{Al}_{2} \mathrm{O}_{3}$ which has done by Bulavchenko et al. [12] showed that reduction occurred through the formation of $\mathrm{CoO}$ and then the metallic fcc cobalt phase. The temperature for the onset of reduction from $\mathrm{Co}_{3} \mathrm{O}_{4}$ to $\mathrm{CoO}$ was $180{ }^{\circ} \mathrm{C}$ and metallic cobalt appeared at $260{ }^{\circ} \mathrm{C}$. The average particle size for fcc cobalt was $7 \mathrm{~nm}$. Kitakami et al. [17] has also reported that the cobalt structure is particle size dependent. Particles smaller than $20 \mathrm{~nm}$ were fcc, those larger than $40 \mathrm{~nm}$ were hcp, while the particles with the size about $30 \mathrm{~nm}$ were a mixture of both fcc and hcp. An increased activity for $\mathrm{CO}$ conversion in FT conditions for hep as opposed to fcc cobalt supported on $\gamma-\mathrm{Al}_{2} \mathrm{O}_{3}$ has been reported [11].

Bulavchenko et al. [12] reported a high concentration of stacking faults, according to analysis of x-ray diffraction peaks. By contrast, the level of planar stacking observed in the metallic cobalt particles observed here was low.

The catalysts particles and support can be distinguished from their morphology, even where their lattice spacing may overlap with other phases. According to Table 1, there is a potential overlap of metallic cobalt spacings with the $\mathrm{CoAl}_{2} \mathrm{O}_{4}$ phase (400) spacing. Cobalt aluminate formation has been reported in the presence of $\mathrm{H}_{2} \mathrm{O}$. Jongsomjit et al. [13] detected surface-formation of $\mathrm{CoAl}_{2} \mathrm{O}_{4}$ phases by Raman spectroscopy. The volume of catalyst present in the ETEM is orders of magnitude smaller than is present at laboratory or commercial reduction process and it is not considered that enough $\mathrm{H}_{2} \mathrm{O}$ would be liberated to produce $\mathrm{CoAl}_{2} \mathrm{O}_{4}$ phases. Furthermore, EELS showed the presence of pure cobalt when effects due to overlapping of the support were avoided and no evidence of the formation of $\mathrm{CoAl}_{2} \mathrm{O}_{4}$ due to residual $\mathrm{H}_{2} \mathrm{O}$ in the vacuum was observed.

The transitional $\mathrm{CoO}$ was not observed during reduction here, presumably due to the fact that it reduces rapidly. $\mathrm{CoO}$ was observed as a reoxidation product during cooling, as the cobalt nanoparticles reoxidized. It is interesting to note that they are not readily passivated by a uniformly thin oxide layer. The reason for the reoxidation is believed to be the presence of $\mathrm{H}_{2} \mathrm{O}$ in the vacuum system, as observed by residual gas analysis. These trace amounts can enter the system via O-ring seals in the microscope.

As mentioned in the introduction, earlier TEM studies on the ex-situ and in-situ reduction of cobalt oxide particles showed the reduction of $\mathrm{Co}_{3} \mathrm{O}_{4}$ to $\mathrm{CoO}$, but not to metallic Co [4, 14]. For a ruthenium promoted catalyst, the distribution of the promoter was not homogeneous and smaller $\mathrm{Ru}$ and $\mathrm{Ru}-\mathrm{Co}$ bimetallic particles were reduced, but not larger cobalt particles [4]. In the case of rhenium promoter, the formation of small bimetallic particles in $4.6 \mathrm{wt} . \% \mathrm{Co} /$ 2wt.\%Re was observed by Rønning et al. using EXAFS [18]. In contrast, measurable direct $\mathrm{Re}-\mathrm{Re}$ bonding in a $15 \mathrm{wt} . \% \mathrm{Co} / 1 \mathrm{wt} . \% \mathrm{Re}$ on $\gamma-\mathrm{Al}_{2} \mathrm{O}_{3}$ supported catalysts after reduction was not observed by Jacobs et al. [19]. It has been suggested that an intimate contact between Re and Co is not necessary to obtain the promoting effect [20]. In the present study, no evidence of an inhomogeneous distribution of rhenium in the promoted material was observed, either in reduced or non-reduced conditions. This suggests that the observed reduced particles were essentially cobalt particles. This behaviour was confirmed in a similar nonpromoted sample, where the catalyst particles are known to be pure cobalt.

In the earlier studies the cobalt oxide particles were supported on $\gamma-\mathrm{Al}_{2} \mathrm{O}_{3}$, which has significantly different pore characteristics from $\alpha-\mathrm{Al}_{2} \mathrm{O}_{3}$. The nanoparticles interact more readily with the support [21] making them more difficult to reduce. Preliminary reduction experiments performed on $\gamma-\mathrm{Al}_{2} \mathrm{O}_{3}$ catalysts in the ETEM, confirmed that they were more difficult to reduce and that the degree of reduction was not so easy to establish due to the more complicated microstructure.

Recent TEM studies report on the observation of metallic cobalt nanoparticles regularly dispersed in a polymer matrix [22, 23]. In these studies decomposition of organometallic precursors in the presence of a reactive gas produced metallic cobalt nanoparticles. In another study cobalt nanoparticles were obtained by evaporation of cobalt foil at $\sim 1500{ }^{\circ} \mathrm{C}$ in a small high vacuum chamber followed by condensation to ultrafine powders [24]. The powders were then oxidized by small doses of $\mathrm{O}_{2}$ giving a 
layer of oxide surrounding the cobalt bulk and then the powder was collected on a $\mathrm{Cu}$ substrate. In all these cases, the cobalt metal surface was protected from oxidation.

The observation reported here illustrate both the high reactivity of the clean cobalt metal surface and the importance of strong control of the gas composition in order to study the kinetics of the interaction with gas compositions that are relevant to the FT process at the atomic scale.

\section{Conclusions}

TEM studies of $12 \mathrm{wt} . \% \mathrm{Co} / 0.5 \mathrm{wt} . \% \mathrm{Re} / \alpha-\mathrm{Al}_{2} \mathrm{O}_{3}$ and $12 \mathrm{wt} . \% \mathrm{Co} / \alpha-\mathrm{Al}_{2} \mathrm{O}_{3}$ catalysts show that it is possible to study the reduction process of the samples in-situ at $\sim 3.4$ mbar. The reduction behaviour of the promoted and non-promoted catalysts was generally similar. High resolution images combined with EELS and HAADF imaging confirm the presence of metallic cobalt and show clearly the changes in morphology of the catalyst nanoparticles and their aggregates. HRTEM gives information about the nanoparticles crystallography, while STEM gives good morphological detail. On reduction, metal particles tend to separate, keeping a large relative surface area. It is shown that careful measurements of lattice parameters allow fcc and hcp metallic cobalt to be distinguished. Measurements of lattice spacings suggested that the majority of particles had the fcc cobalt structure and confirms the suppression of hcp crystal structure for small nanoparticles. It was also found that the levels of planar faults were low.

Reoxidation of the particles underlines the high reactivity of cobalt nanoparticles. The clean cobalt metal surface is extremely sensitive to trace gases present in the vacuum system. Qualitatively similar observations are made for a similar non-promoted catalyst. The distribution of the $\mathrm{Re}$ in the promoted catalysts appeared to be quite uniform. The methods used are promising for the future insitu studies of cobalt-based FT systems.

Acknowledgments The financial support from Research Council of Norway and Statoil is greatly acknowledged. This publication forms a part of the inGAP Centre of Research-based Innovation, which receives financial support from the Norwegian Research Council under contract no. 174893. The ETEM experiments were done at the Center for Electron Nanoscopy at the Technical University of Denmark (DTU). The A. P. Møller and Chastine Mc-Kinney Møller Foundation is gratefully acknowledged for their contribution towards the establishment of the Center for Electron Nanoscopy. Rafal E. Dunin-Borkowski is gratefully acknowledged for valuable discussion.
Julian Tolchard is gratefully acknowledged for doing XRD experiments.

Open Access This article is distributed under the terms of the Creative Commons Attribution Noncommercial License which permits any noncommercial use, distribution, and reproduction in any medium, provided the original author(s) and source are credited.

\section{References}

1. Khodakov AY (2009) Catal Today 144:251-257

2. Dry ME (2002) Catal Today 71:227-241

3. Boyes ED, Gai PL (1997) Ultramicroscopy 67:219-232

4. Li P, Liu J, Nag N, Crozier PA (2006) Appl Catal A Gen 307:212-221

5. Gai PL, Boyes ED (2009) Microsc Res Techniq 72:153-164

6. Hansen TW, Wagner JB, Dunin-Borkowski RE (2010) Mater Sci Technol 26(11):1338-1344

7. Giorgio S, Joao SS, Nitsche S, Chaudanson D, Sitja G, Henry CR (2006) Ultramicroscopy 106:503-507

8. Smith WL, Hobson AD (1973) Acta Cryst B29:362-363

9. Powder diffraction file, Inorganic phases, International centre for diffraction data, (1986), p 532, 538, 680, 1049

10. Troiano AR, Tokich JL (1948) Trans AIME 175:728

11. Ducreux O, Rebours B, Lynch J, Roy-Auberger M, Bazin D (2009) Oil Gas Sci Technol Rev IFP 64:49-62

12. Bulavchenko OA, Cherepanova SV, Malakhov VV, Dovlitova LS, Ishchenko AV, Tsybulya SV (2009) Kinet Catal 50(2): 192-198

13. Jongsomjit B, Panpranot J, Goodwin JG Jr (2001) J Catal 204:98-109

14. Ozkaya D, Lok M, Casci J, Ash P (2006) IMC16 Sapporo, vol 3. p 1561

15. Gai PL, Boyes ED (2003) Electron microscopy in heterogeneous catalysis. Institute of Physics Pub, London

16. Freitag B, Kujawa S, Mul PM, Ringnalda J, Tiemeijer PC (2005) Ultramicroscopy 102:209-214

17. Kitakami O, Sato H, Shimada Y (1997) Phys Rev B 56(21):13849-13854

18. Rønning M, Nicholson DG, Holmen A (2001) Catal Lett 72(3-4):141-146

19. Jacobs G, Chaney JA, Patterson PM, Das TK, Davis BH (2004) Appl Catal A 264:203-212

20. Hilmen AM, Schanke D, Holmen A (1996) Catal Lett 38:143-147

21. Borg Ø, Walmsley JC, Dehghan R, Tanem BS, Blekkan EA, Eri S, Rytter E, Holmen A (2008) Catal Lett 126:224-230

22. Verelst M, Ely TO, Amiens C, Snoeck E, Lecante P, Mosset A, Respaud M, Broto JM, Chaudret B (1999) Chem Mater 11:2702-2708

23. Respaud M, Broto JM, Rakoto H, Fert AR, Thomas L, Barbara B, Verelst M, Snoek E, Lecante P, Mosset A, Osuna J, Ely TO, Ameniens C, Chaudret B (1998) Phys Rev B 57(5):2925-2935

24. Sayagues MJ, Rojas TC, Fernandez A, Dunin-Borkowski RE, Doole RC, Hutchison JL (2002) Microsc Microanal 8:403-411 